\title{
Standard of Care and Transparency in Clinical Trials Conducted in Developing Countries of Africa
}

\author{
Pia Mielczarek ${ }^{1}$, Anna Streichhardt ${ }^{1}$, Dnyanesh Limaye ${ }^{1}$, Vaidehi Limaye ${ }^{1}$, Firas Fneish ${ }^{1,2}$, \\ Gerhard Fortwengel ${ }^{1}$ \\ ${ }^{1}$ Faculty III Information and Communication, Hochschule Hannover University of Applied Sciences and Arts, Hannover, Germany \\ ${ }^{2}$ Institute of Biostatistics, Leibniz University Hannover, Hannover, Germany
}

Email address:

anna.streichhardt@gmx.de (A. Streichhardt)

\section{To cite this article:}

Pia Mielczarek, Anna Streichhardt, Dnyanesh Limaye, Vaidehi Limaye, Firas Fneish, Gerhard Fortwengel. Standard of Care and Transparency in Clinical Trials Conducted in Developing Countries of Africa. Central African Journal of Public Health.

Vol. 5, No. 2, 2019, pp. 92-97. doi: 10.11648/j.cajph.20190502.15

Received: August 30,2018; Accepted: February 26, 2019; Published: March 28, 2019

\begin{abstract}
Background: Clinical trials are conducted all over the world, including developing economies in Africa. Pharmaceutical companies could easily take advantage of the regulatory situation in these vulnerable countries. This research study examines ethical statements of the 25 top pharmaceutical companies conducting clinical trials in Africa regarding three questions in objectives according to their policies or their websites. Objectives: 1. Do pharmaceutical companies mention clinical trials in developing countries? 2. Do pharmaceutical companies mention the issue with standard of care? 3. Do pharmaceutical companies mention NDA (New Drug Application) and special prices for countries and participants? Methods: To evaluate the statements found in their policies or websites, a rating scale with a maximum of 10 points was developed. The statements of the pharmaceutical companies have been rated by at least two independent researchers. High points are equal to high standards, the maximum points were 10. Results: Only 15 out of the biggest 25 pharmaceutical companies were conducting at least 10 clinical trials in developing countries in Africa during the last five years. On average, the pharmaceutical companies achieved a score of 6.93 of 10. Conclusion: On one hand, the result shows that some companies achieved high scores. On the other hand, it shows that some companies need to improve their policies and statements of commitment to serve as a role model.
\end{abstract}

Keywords: Developing Countries, Clinical Trials, Standard of Care, Transparency, Pharmaceutical Companies, Africa

\section{Introduction}

Clinical trials are conducted worldwide to provide evidence of safety and efficacy of potential new medicinal products. Randomized controlled trials (RCTs) form the most accepted design in drug development and are considered as the 'gold standard'. In placebo-controlled trials ethical concerns about placebo use must be considered and create in particular a topic of debate when an effective therapy is available [1].

In accordance with the principle that every subject must receive the best treatment in the world, controlled clinical trials in developing countries require special attention. Considering the fact that in those countries a standard treatment is often not available, implementation of a control group receiving placebo includes the risk of exploitation of host communities. This scenario becomes even more complex when an effective treatment is on the market in Western countries [2].

Available reports showed that many pharmaceutical companies conduct clinical trials in developing countries in Africa [3, 5] and make use of various attractive advantages. Such advantages may include cost effectiveness vis a viz cheap labour and logistic requirements. In addition, the less stringent regulatory framework and faster approvals from the relevant regulatory bodies might translate to reduced cost and sooner track to drug availability in the market [3].

From an ethical perspective of African regulatory bodies, lower healthcare standards in most African developing countries enhances the attraction that through clinical trials 
the quality of care could be improved by launching new drugs in the local market. [4]

However, considering the weak regulatory framework in many developing countries, the vulnerability of the local population becomes obvious. These factors heighten the possibility of ethical misconduct by pharmaceutical companies. [6]

It should be figured out how this dilemma can be approached and what actions are needed to safeguard local populations in these countries regarding clinical trial participation. One option brings us to the much-cited transparency requirement in clinical research. Usually transparency refers to the need to document any clinical trial in a publicly accessible trial registry and to publish the results after study completion. It is not known whether this information is also provided in the company policies. As a first step, answers to the following questions are required. Do sponsors mention in company policies:

i. Clinical trials in developing countries?

ii. The issue with standard of care?

iii. NDA (New Drug Application) and other benefits for countries and participants?

\section{Methods}

As a first step for this study, the country classification of the UN was accessed. Table C Developing economies by region (Part developing economies in Africa) was used as reference [7]. In the next step the top 25 pharma companies were searched by global sales in 2016, based on information from the website "statista" [8].

For answering the three questions, it was necessary to have information about these 25 pharma companies conducting clinical trials in developing economies in Africa. Therefore, the database clinicaltrials. gov was searched with the following filters: open studies and time period from 1.1.2011 until 02.11.2016. Keywords for this search were company name as "exact match" as well as every country of the developing economies of Africa.

The identified companies were searched on their websites and Google for publicly accessible policies. Detailed steps of the search are documented in figure 1.

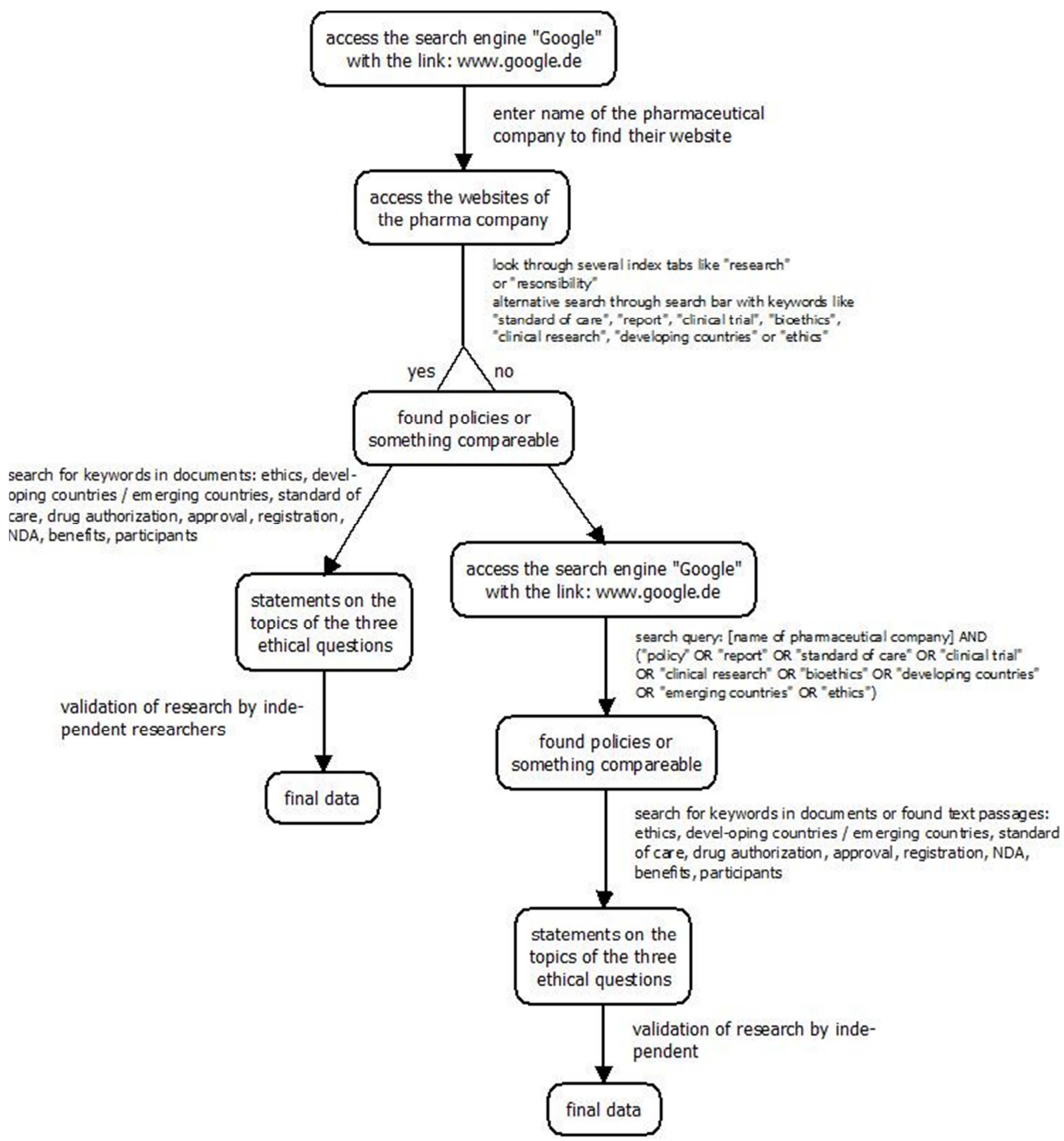

Figure 1. Search for policies of pharmaceutical companies. 
In order to evaluate the different statements, following rating scale was developed as shown in table 1.

Table 1. Rating scale for pharmaceutical companies conducting clinical trials in developing economies in Africa.

\begin{tabular}{|c|c|c|c|c|c|}
\hline \multicolumn{6}{|c|}{ RATING SCALE FOR PHARMACEUTICAL COMPANIES } \\
\hline \multicolumn{6}{|c|}{ 1. DO THEY MENTION CLINICAL TRIALS IN DEVELOPING COUNTRIES? } \\
\hline Description & not mentioned & $\begin{array}{l}\text { Not clearly } \\
\text { something unspecific is } \\
\text { mentioned which can be } \\
\text { interpreted with good will }\end{array}$ & $\begin{array}{l}\text { Yes } \\
\text { conducting clinical } \\
\text { trials in developing } \\
\text { countries }\end{array}$ & $\begin{array}{l}\text { Yes, if it is need } \\
\text { where the medicines are } \\
\text { likely to be suitable for } \\
\text { the countries }\end{array}$ & \\
\hline Score & 0 & 1 & 2 & 3 & \\
\hline \multicolumn{6}{|c|}{ 2. DO THEY MENTION THE ISSUE WITH STANDARD OF CARE? } \\
\hline Description & not mentioned & $\begin{array}{l}\text { Not clearly } \\
\text { something unspecific is } \\
\text { mentioned which can be } \\
\text { interpreted with good will }\end{array}$ & $\begin{array}{l}\text { Not exactly } \\
\text { following officially } \\
\text { recognized ethical } \\
\text { standards* }\end{array}$ & $\begin{array}{l}\text { Yes } \\
\text { issue is mentioned with } \\
\text { the position of the } \\
\text { company }\end{array}$ & \\
\hline Score & 0 & 1 & 2 & 3 & \\
\hline \multicolumn{6}{|c|}{ 3. DO THEY MENTION NDA AND SPECIAL PRICES FOR COUNTRIES AND PARTICIPANTS? } \\
\hline Description & not mentioned & $\begin{array}{l}\text { Not clearly } \\
\text { something unspecific is } \\
\text { mentioned which can be } \\
\text { interpreted with good will }\end{array}$ & $\begin{array}{l}\text { Yes, with access } \\
\text { participants get } \\
\text { medical access after } \\
\text { the trial }\end{array}$ & $\begin{array}{l}\text { Yes, with NDA } \\
\text { NDA of product in these } \\
\text { countries }\end{array}$ & $\begin{array}{l}\text { Yes, with special prices } \\
\text { special prices for the } \\
\text { developing countries }\end{array}$ \\
\hline Score & 0 & 1 & 2 & 3 & 4 \\
\hline
\end{tabular}

* e.g. Declaration of Helsinki, GCP

In total a score of 10 could be achieved.

Hits of these keywords were analyzed by matching documents or statements and if possible transformed in the best fitting rating scale score. Minimum one independent researcher evaluated this search.

If there were any unclear statements, the quotes of them has been discussed in its context. Every given score has been discussed in the research team including five to six independent group members.

\section{Results}

Only 15 out of the biggest 25 pharma companies worldwide were conducting at least 10 clinical trials in these countries during the last five years [9]. Figure 2 highlights the total score of 15 pharmaceutical companies on three ethical Parameters.

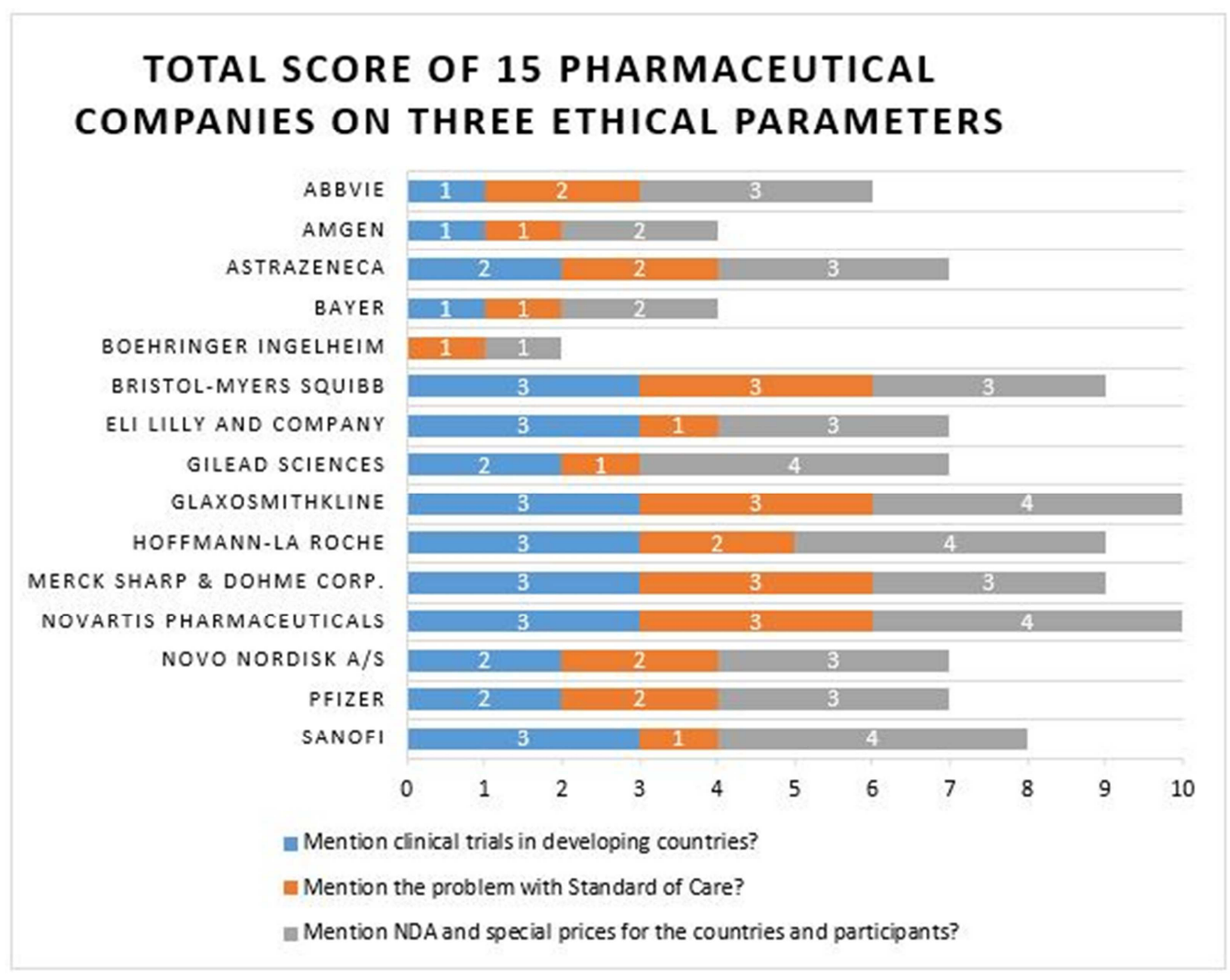

Figure 2. Total score of 15 Pharmaceutical Companies sorted alphabetically using the developed rating scale. 
Question 1: Mention clinical trials in developing countries?

For the first question $46.7 \%(7 / 15)$ companies had a score of 3 out of 3 . Policies of these companies mentioned conducting the trials where the medicines are likely to be suitable for the countries. $26.7 \%(4 / 15)$ of the companies reached a score of 2 out of 3 , indicating conducting clinical trials in developing countries without specifying the need for the country. $20 \%(3 / 15)$ companies had a score of 1 out of 3 . There was no clear statement of conducting clinical trials in developing economies in Africa in their policies. One company did not mention anything about conducting of clinical trials in the developing economies in Africa on their website or in any policy.

Question 2: Mention the problem with Standard of Care?

Regarding the second question, 26.7\% (4/15) companies had a score of 3 out of 3 . This means, Policies of these companies mentioned conducting the trials where the issue is mentioned with the position of the company. 33.3\% (5/15) of the companies achieved a score of 2 out of 3 , indicating following officially recognized ethical standards like Declaration of Helsinki or GCP. 40\% (6/15) companies had a score of 1 out of 3 . There was no clear statement of conducting clinical trials in developing economies in Africa in their policies.

Question 3: Mention NDA and special prices for the countries and participants?

$33.3 \%(5 / 15)$ companies reached a score of 4 out of 4 . Policies of these companies mentioned NDA and specified to market their products with affordable prices for the developing countries. $46.6 \%(7 / 15)$ of the companies reached a score of 3 out of 4 , indicating a NDA of the investigational product in these countries. $13.3 \%(2 / 15)$ companies had a score of 2 out of 4 , this implies that participants get access to the investigational medical product (IMP) after the trial. One company had no clear statement about NDA or access to the IMP after closing the study sites in the countries conducting the trial.

An example for achieving one point in the first question (Mention clinical trials in developing countries?) is Amgen: "Amgen strives to maintain high ethical principles, as well as high scientific and clinical standards in all of its clinical trials regardless of where they take place." The company says they always take care of ethical principles of where the clinical trials take place, but do not especially include developing economies and how they deal with special issues in these countries.

Bayer achieved one point for the Question "Do they mention the problem with Standard of Care?". Bayer does not mention the problem directly, but says they are involved in a Research initiative, which endorses the goals of the World Health Organization (WHO). Furthermore, they affirm to "conduct clinical trials in accordance with the international guidelines, the current national and local laws and regulations and the highest medical, scientific and ethical principles".
Boehringer Ingelheim achieved one point in the last question "Do they mention NDA and special prices for the countries and participants?". In their policy it refers to its mission for bringing "high quality medication to the people who need it - at affordable prices for patients and healthcare institutions". In Addition to this statement, it mentions "a tiered pricing model for their alteplase medication, which is used in the thrombolytic treatment of acute ischaemic stroke". This pricing model is initiated in Colombia, Ecuador and Brazil. However, Africa is not mentioned. As mentioned below, Boehringer Ingelheim supports significant extension of access to the active substance nevirapine (for HIV treatment) in developing countries.

"In order to substantially extend access to the active ingredient nevirapine, Boehringer Ingelheim decided to not enforce its patents and offers interested generic manufactures listed on the WHO pre-qualification programme (or being FDA approved) non-assert declarations enabling them at no additional costs to supply nevirapine-containing medicines for eligible countries." [10]

Boehringer Ingelheim specifically mentions availability of affordable medicines for specific conditions like HIV and ischaemic stroke for developing countries. However, it makes no mention of improving access to affordable medications in general. Therefore, they only achieved one point in the rating scale.

\section{Discussion}

In general, it should be asked if transparency should demand potential sponsors to explain, how they stand up to the question of standard of care in clinical research. Additionally, it should be questioned, whether a New Drug Application is filed in any of the countries in which clinical studies have been conducted, to improve the standard of care through market availability of new medications.

Transparency is very important in clinical research. With this, the sponsors of clinical trials increase their responsibility to the public by guaranteeing that they will neither exploit the countries where the research takes place, nor the study staff and the trial participants. [11]

Generally, in clinical research, transparency is understood with reference to the publication of study results. But also, the sponsors' transparency about doing a clinical trial in a specific country should be considered. In this case, transparency is defined as intentions of the sponsors, which are open to the public, regarding the advantages and disadvantages of conducting clinical trial in that country. There is inequality in bargaining power between the developing countries in which clinical research takes place and the sponsors from the developed countries. This might lead the community in the developing countries itself to agree to an unfair level of benefits. [12]

To avoid this and to create fairness towards developing countries as a research site, sponsors should publicly present intentions in their policy. This could also aid in decision 
making for developing countries, if they want to allow sponsors to carry out clinical research in their country. The term 'standard of care' can be defined in multiple ways. On one hand wherein the local or national standard of care is defined as "the level of care that ought to be delivered under conditions of appropriate and efficient referral in a national system" [13]; on other hand, international / global standard of care is defined as the level of care which is available worldwide. Due to the differences in defining 'standard of care', it is possible for sponsors of clinical studies to conduct placebo-controlled studies in developing countries. Such a study design often complies with the national standard of care. This issue leads to the conduct of trials, such as placebo-controlled HIV studies. However, based on the international / global standard of care, this design would be considered legally unethical. [13] According to the World Medical Association (WMA) revised version of the Declaration of Helsinki, all study participants should be treated according to the worldwide standard of care. [12] Accordingly, it would be desirable for sponsors of clinical trials to adhere to the standards set forth in the Declaration of Helsinki. Gathering useful data from developing countries where study participants receive less than the world's best care is unethical. This creates a double standard of practice, which is implemented for the poor and rejected for the rich for being unethical. An existing practice of lower standard of care in clinical research deserves further examination. [14]

For clinical research to be 'ethical', the population of developing countries, where clinical research takes place, should also benefit from it. This means that the sponsors / pharmaceutical companies should also allow the tested drugs there and make them available in the local market. [15] However, only the approval of new drugs is not enough to raise the standard of care for developing countries. In order to make the new drug accessible to the local population, the sponsors / pharmaceutical companies must adjust the selling prices to the local market, so that the population can afford the drug. [16]

Three pharmaceutical companies, which achieved a score below five points in the present study, should thoroughly revise their policies. They should pay more attention to the transparency of their intentions in relation to study sites, especially in developing countries, and to understand their importance.

For the first question, three pharmaceutical companies scored only one point, and one pharmaceutical company failed to score any points. This means that the pharmaceutical companies who scored one point had an unspecific response regarding this question. Mention of conducting clinical trials in developing countries could be interpreted only with good will. The company, which has reached no point in the first question, has made no public statement on this issue and completely neglected this topic in their policy.

In total, six pharmaceutical companies only achieved a single point on the second question highlighting the problem with standard of care in their policies. Also for this question, as previously mentioned, interpretation was possible with a good will only. The fact that $40 \%$ of the pharmaceutical companies from the present study achieved only one out of three points on this question may reflect their disinterest in improving the local standard of care. [13]

Only one pharmaceutical company scored one point for the third question about NDA and special prices for the participants and countries in which the clinical research takes place. In this case, it also meant that their response was unspecific and could be interpreted with good will only.

\section{Conclusion}

In the present study, the pharmaceutical companies achieved an average score of 6.93 of 10 , which could have been better. Only five pharmaceutical companies scored the highest points between 9 and 10 . The pharmaceutical companies reaching a middle-ranged score (score of 6 to 8 ) should not be taken in a bad light, but they need to improve their policy statements and its implementation.

The policies of GlaxoSmithKline and Novartis Pharmaceuticals can serve as a role model for the other pharmaceutical companies. These two companies scored the full 10 points. This indicates that these companies are well aware of the importance of transparency in their intentions towards their research sites and their commitments to developing countries.

Every pharmaceutical company should become a role model in transparency. This will enable the regulatory authorities and ethics committees to make an informed decision of allowing the conduct of clinical studies for these companies. This could also improve the local standard of care and benefit the study sites from the clinical research. Transparency and standard of care in clinical trials should go hand in hand for the benefit of study participants from developing countries.

\section{References}

[1] Nallamothu BK, Hayward RA, Bates ER. Beyond the randomized clinical trial: the role of effectiveness studies in evaluating cardiovascular therapies. Circulation. 2008; 118: 1294-303.

[2] Weijer C, Shapiro SH, Glass KC. Clinical equipoise and not the uncertainty principle is the moral underpinning of the randomised controlled trial. BMJ 2000; 321 (7263): 756-758.

[3] Glickman SW, McHutchison JG, Peterson ED, Cairns CB, Harrington RA, Califf RM, et al. Ethical and Scientific Implications of the Globalization of Clinical Research. N Engl J Med 2009; 360: 816-823.

[4] Puppalwar G, Mourya M, Kadhe G, Mane A. Conducting clinical trials in emerging markets of sub-Saharan Africa: review of guidelines and resources for foreign sponsors. Open Access Journal of Clinical Trials 2015; 2015 (7): 23-34.

[5] Maïgaa D, Akanmori BD, Chocarro L. Regulatory oversight of clinical trials in Africa: Progress over the past 5 years. Vaccine 2009; 27: 7249-7252. 
[6] Nardini C. The ethics of clinical trials. ecancer 2014; 8: 387 doi: 10.3332/ecancer.2014.387.

[7] DESA: World Economic Situation and Prospects 2016. United Nations: United Nations publication, 2016.

[8] CStatista 2016. Top 50 Pharmaunternehmen weltweit nach Umsatz und Ausgaben für Forschung und Entwicklung im Jahr 2015 (in Milliarden US-Dollar) [Internet]. 2015.

Available from:

https://de.statista.com/statistik/daten/studie/439880/umfrage/t op-50-pharmaunternehmen-umsatz-und-forschungsausgaben/.

[9] U.S. National Library of Medicine. ClinicalTrials.gov [Internet]. 2016. Available from: https://clinicaltrials.gov/ct2/home.

[10] Boehringer Ingelheim GmbH. Corporate Public Affairs. For Better Health. Access to Healthcare at Boehringer Ingelheim [Internet]. 2015. Available from: https://www.boehringeringelheim.com/sites/default/files/Documents/ForBetterHealth. pdf.

[11] Emanuel EJ, Wendler D, Killen J, Grady C. What Makes Clinical Research in Developing Countries Ethical? The Benchmarks of Ethical Research. JID 2004; 189: 930-937.
[12] El Setouhy M, Agbenyega T, Anto F, Clerk CA, Koram KA, English M, et al. Fair Benefits for Research in Developing Countries. SCIENCE 2002; 298: 2133-2134.

[13] Hyder AA, Dawson L. Defining standard of care in the developing world: The intersection of international research ethics and health systems analysis. Developing World Bioethics. 2005; 5 (2): 1471-8847.

[14] Lie RK, Emanuel EJ, Grady C, Wendler D. The standard of care debate: the Declaration of Helsinki versus the international consensus opinion. J Med Ethics 2004; 30: 190193.

[15] Hawkins JS, Emanuel EJ: Exploitation and Developing Countries. The Ethics of Clinical Research. New Jersey: Princeton University Press, 2008.

[16] Boseley S. Big Pharma ups its game in providing drugs to people in poor countries. Access to Medicines Index shows pharmaceutical companies improving on pricing, neglected diseases, lobbying and trials. theguardian [Internet]. 2012. Available from: https://www.theguardian.com/globaldevelopment/2012/nov/28/big-pharma-drugs-poor-countries. 